\author{
Asian Journal of \\ Medical and Biological Research \\ ISSN 2411-4472 (Print) 2412-5571 (Online) \\ www.ebupress.com/journal/ajmbr
}

\title{
Article \\ Socio-economic condition of fishermen and intermediaries involved in marine fish marketing chain in Cox's Bazar area, Bangladesh
}

Md. Khabirul Ahsan ${ }^{1}$, Nusrat Sultana Runa ${ }^{2}$, Subrata Kumar Ghosh ${ }^{3}$, Muhammad Mehedi Hasan ${ }^{1}$ and Md. $\mathrm{Kamal}^{1 *}$

${ }^{1}$ Department of Fisheries Technology, Faculty of Fisheries, Bangladesh Agricultural University, Mymensingh2202, Bangladesh

${ }^{2}$ Faculty of Agricultural Economics and Rural Sociology, Bangladesh Agricultural University, Mymensingh2202, Bangladesh

${ }^{3}$ Department of Fishing and Post Harvest Technology, Faculty of Fisheries, Chittagong Veterinary and Animal Sciences University, Chittagong-4225, Bangladesh

"Corresponding author: Md. Kamal, Department of Fisheries Technology, Bangladesh Agricultural University, Mymensingh-2202, Bangladesh. E-mail: mkamal772011@gmail.com

Received: 25 February 2016/Accepted: 20 March 2016/Published: 31 March 2016

\begin{abstract}
Study was conducted to know the socio-economic condition of the fishermen and intermediaries of fish marketing chain in Cox's Bazar area, Bangladesh. Socio-economic condition of the fishermen and intermediaries were not so good in the study area. It was found that about $35 \%$ fishermen and intermediaries were illiterate, $16 \%$ fishermen and intermediaries were semiliterate who only could write their names. $55 \%$ household of the fishermen and intermediaries had tin shed house with tin wall. Average income for most of fishermen and intermediaries was about Tk. 400-500 and 66\% were found to borrow money from different source for continuing their business. Poor road and transport facilities, lack of credit facilities, insufficient supply of ice, inadequate training facilities and large number of intermediaries in the chain were the main problems of the marine fish marketing chain. It is therefore necessary to provide institutional and organizational support, government support, extension service and training facilities to the market operators for sustainable fish marketing systems.
\end{abstract}

Keywords: socio-economic; marine fish; fishermen; Intermediaries; Cox's Bazar

\section{Introduction}

The socio economic aspect describes the present status of income, expenditure, housing condition, health and sanitation, education, family structure and other economic condition. Some of the most commonly used factors in the assessment of livelihood security included those related to household income and expenditure, expenditure spent on food, adequacy of food taken, household structure and facilities, and access to drinking water and sanitation, and other basic needs of farm household (Rahman et al., 2012). For planning, decision making and developing the fisheries sector, it is necessary to know the socio economic condition of the related people. Besides the socio economic condition of the fishermen and intermediaries are changing day by day. For this reason it is necessary to know the present socio economic condition of the fishermen and intermediaries.

\section{Materials and Methods}

The study about socio-economic condition of the fishermen and intermediaries involved in marine fish marketing was conducted in Cox's Bazar Upazila under the district of Cox's Bazar. Combinations of participatory, qualitative and quantitative methods were used for primary data collection. In order to get a representative picture of the socio-economic condition of the fishermen and intermediaries involved in marine fish marketing chain, following groups of people were selected: fishermen, wholesalers, depot owner and 
retailer.

Sampling is an important part of survey based research. Total sample size of the study was 120 which mainly comprised of 45 fishermen, beparis and depot owner, 40 brokers and marketing agents, and 35 retailers. Questionnaire was prepared for collecting relevant information of the study.

\subsection{Data collection methods}

Primary data were gathered by field survey. Data were collected for six months from November 2014 to April 2015. Combinations of participatory, qualitative and quantitative methods were used for data collection.

\subsubsection{Participatory rural appraisal (PRA)}

PRA is a group of methods to collect information in a participatory basis from rural communities. The advantage of PRA over other methods is that it allows a wider participation of the community, the information collected is likely to be more accurate (Chambers, 1992; Nabasa et al., 1995).

\subsubsection{Questionnaire survey}

For questionnaire survey different market operators such as fishermen, assemblers, wholesalers and retailers were interviewed. The interviews focused on the socio-economic condition of the fishermen and intermediaries involved in fish marketing. Collected data were analyzed using Microsoft Excel.

\subsection{Data processing and analysis}

After collection, the data were scrutinized and carefully edited to eliminate possible errors and inconsistencies contained in the schedules while recording. The first step was to look into the data of each and every interview schedule to ensure consistency and reliability with the aims and objectives of the study. After completing the pre-tabulation task, they were transferred to Excel sheet.

\section{Results}

Results attempts to analyze the prevailing social and economic characteristics of the fishermen and intermediaries of the marine fish marketing chain in Cox's Bazar area of Bangladesh. Data were mainly related to age structure, family size, education status, daily income, credit access issues, ownership of land and house, housing pattern, use of electricity and mobile phone, standard of living, credit supply, sanitation facilities, Health and nutrition, sources of drinking and bathing water etc.

\subsection{Age structure}

The survey revealed that only male fishermen and intermediaries were involved in the marine fish marketing. Fishermen and intermediaries were classified into different age groups. Fishermen and intermediaries from the age group of 31 to 40 years were mainly engaged in marine fish marketing. This group constituted $40 \%$ of total respondents, whereas age group 21 to 30 and 41 to 50 constituted $19 \%$ and $22 \%$ respectively. Contributions from the age below 20 and above 50 are as low as $9 \%$ and $10 \%$ respectively (Figure 1). This might be due to part time fish marketing job and age barrier.

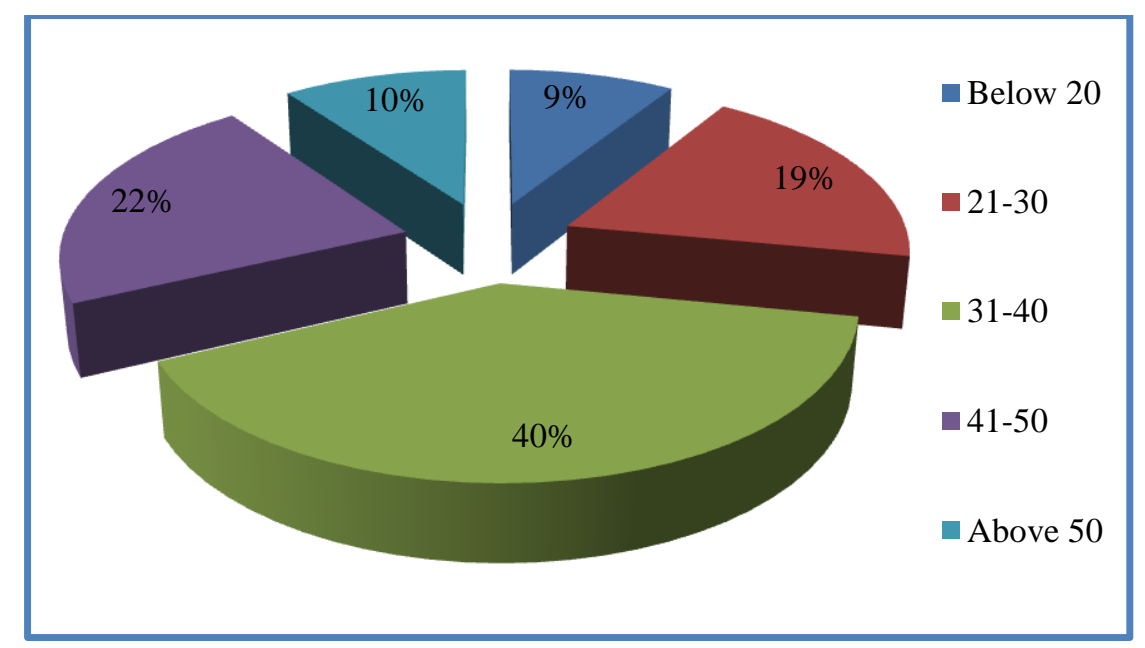

Figure 1. Distribution of age groups of fishermen and intermediaries in the study area 


\subsection{Family size}

Families were classified according to the member i.e. small family with one to four members; medium family with five to six members; large family with seven to eight members; and very large family with nine or more than nine members. The family size was related to the income of the fishermen and intermediaries. Family size also determines the family status and the relationship with the families. In the study $15 \%$ belonged to small family group, $45 \%$ belonged to medium family group, $27 \%$ belonged to large family group and $13 \%$ belonged to very large family group (Figure 2).

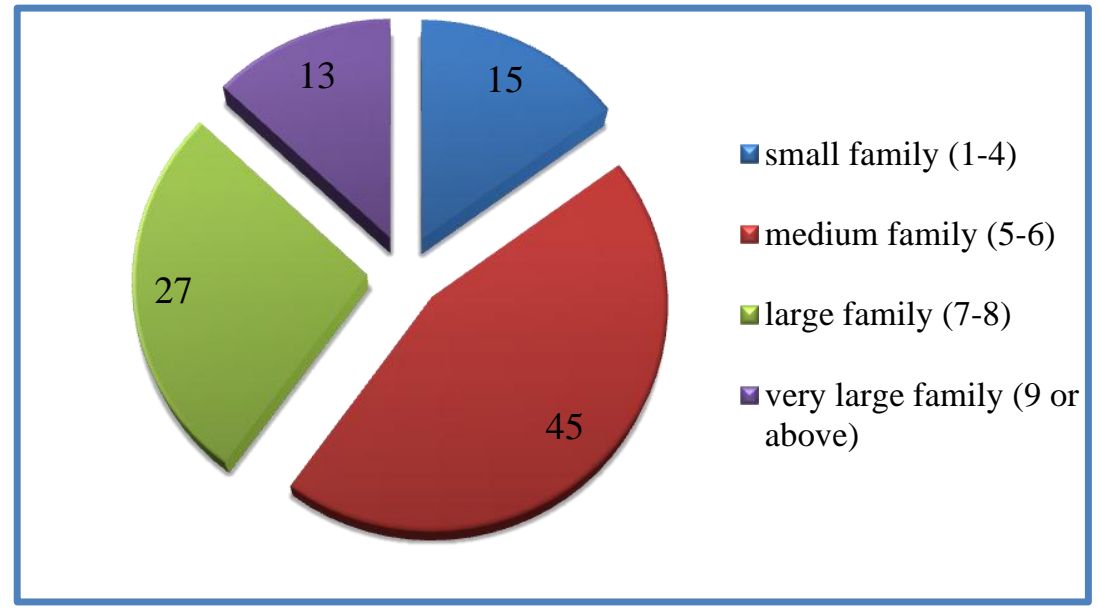

Figure 2. Distribution of family size of fishermen and intermediaries in the study area.

\subsection{Educational status}

Educational qualification influences on individual preferences, behavioral patterns, performance, skillness and capability. The literacy levels of intermediaries were very low. The majority were illiterate whereas only few fishermen and intermediaries had their education up to primary level and some only can write their name and give a signature. Their children went to school till the primary level and onwards they drop-it for income generation. On the contrary, women were also illiterate who do not even know to read. To examine the literacy status of the marine fishermen and intermediaries, the educational status of the respondents was divided into five categories: (a) illiterate; (b) literate: a person who can write a letter for communication (BBS, 2011); (c) primary level (Class I-V); (d) secondary level (Class VI-X) and (e) higher secondary or above. Data obtained from the survey revealed that $35 \%$ fishermen and intermediaries were illiterate, $16 \%$ could only write a letter for communication, $25 \%$ had received education up to primary level, $21 \%$ had received education up to secondary level and 3\% went beyond higher secondary or above (Figure 3). About $80 \%$ children of the fishermen and intermediaries completed primary level of education (up to class V), while the rest (20\%) dropped out before completing primary education.

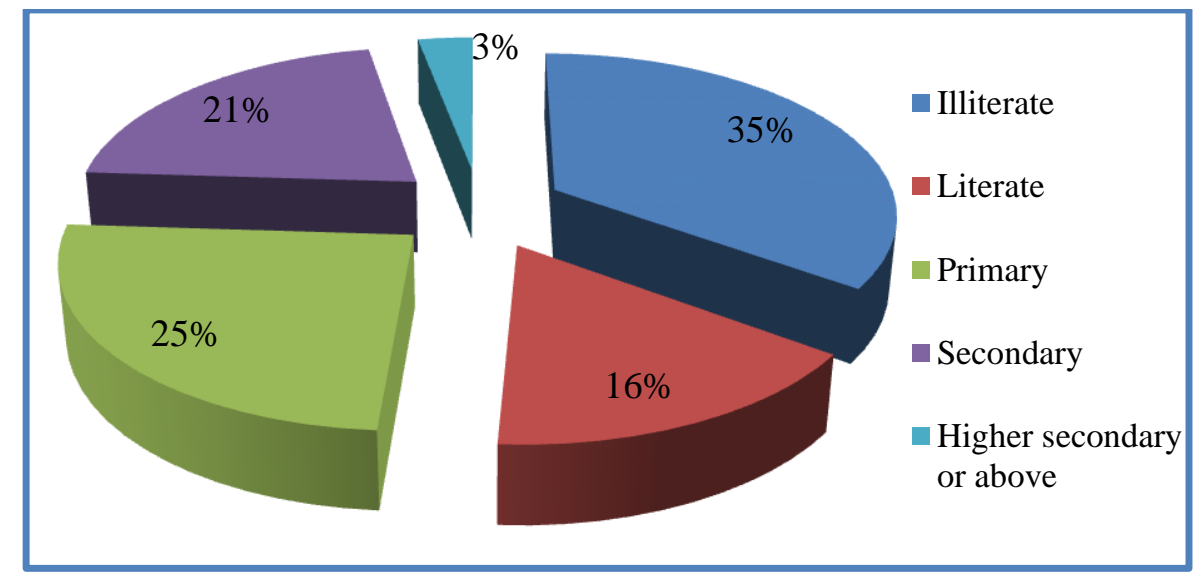

Figure 3. Educational status of the fishermen and intermediaries in the study area. 


\subsection{Daily income pattern}

Daily income is the most important factor for better understanding of socio-economic condition of the intermediaries. The daily income of the intermediaries varied from BDT 200 to BDT 800. During the peak harvesting period, BDT $400-500$ per day was earned by $35 \%$ fishermen and intermediaries. BDT 300-400, BDT 500-600, BDT 200-300, BDT 600-700 and BDT 700-800 per day was earned by $19 \%, 16 \%, 13 \%, 10 \%$ and 7\% fishermen and intermediaries (Figure 4). Respondents reported that there is positive correlation between income and expenditure. When the fish supply in the market decreased, the fishermen and intermediaries dropped to a low income group and thereby faced problems like poverty, illness of family members and diseases.

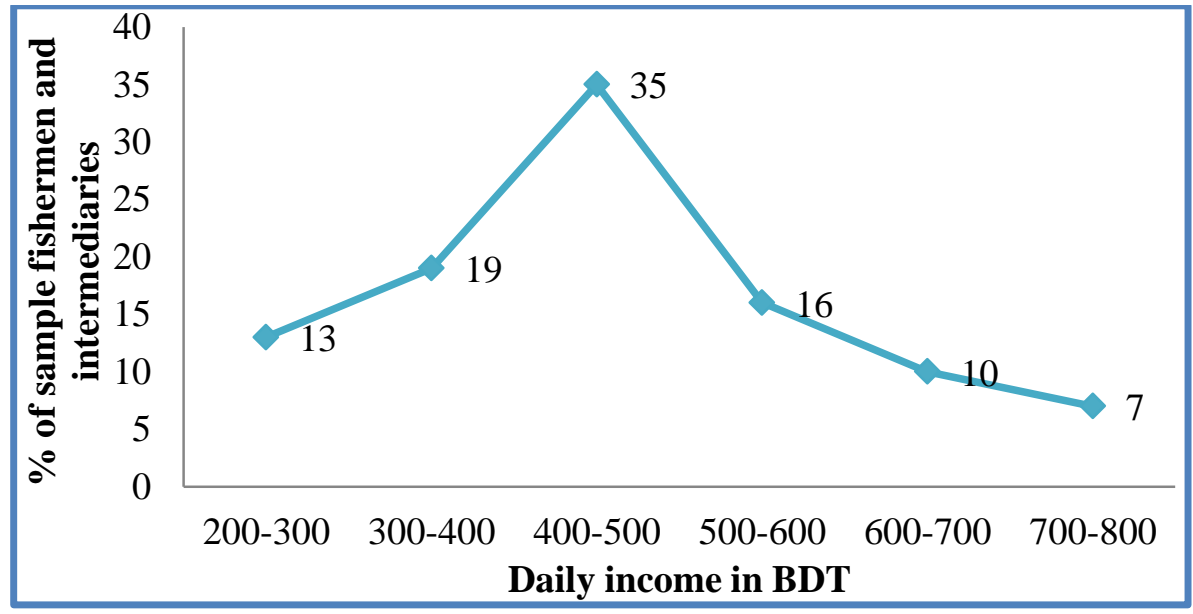

Figure 4. Distribution of daily income pattern of fishermen and intermediaries in the study area.

\subsection{Credit access issues}

The national and local Non-Government Organization (NGO) like BRAC, ASHA provide credit only to the organized poor members for purchasing fishing gears and boats where the interest rate varies from season to season. It is often argued that the amount of credit being provided by the NGOs was insufficient and not commensurate to the poor people's actual need. It was observed that after repayment $34 \%$ became self-sufficient (who did not need financial help), whereas $14 \%$ borrowed money from their neighbors, $17 \%$ from relatives, $24 \%$ from NGOs or bank again and 11\% from co-operatives for their fishing business (Figure 5).

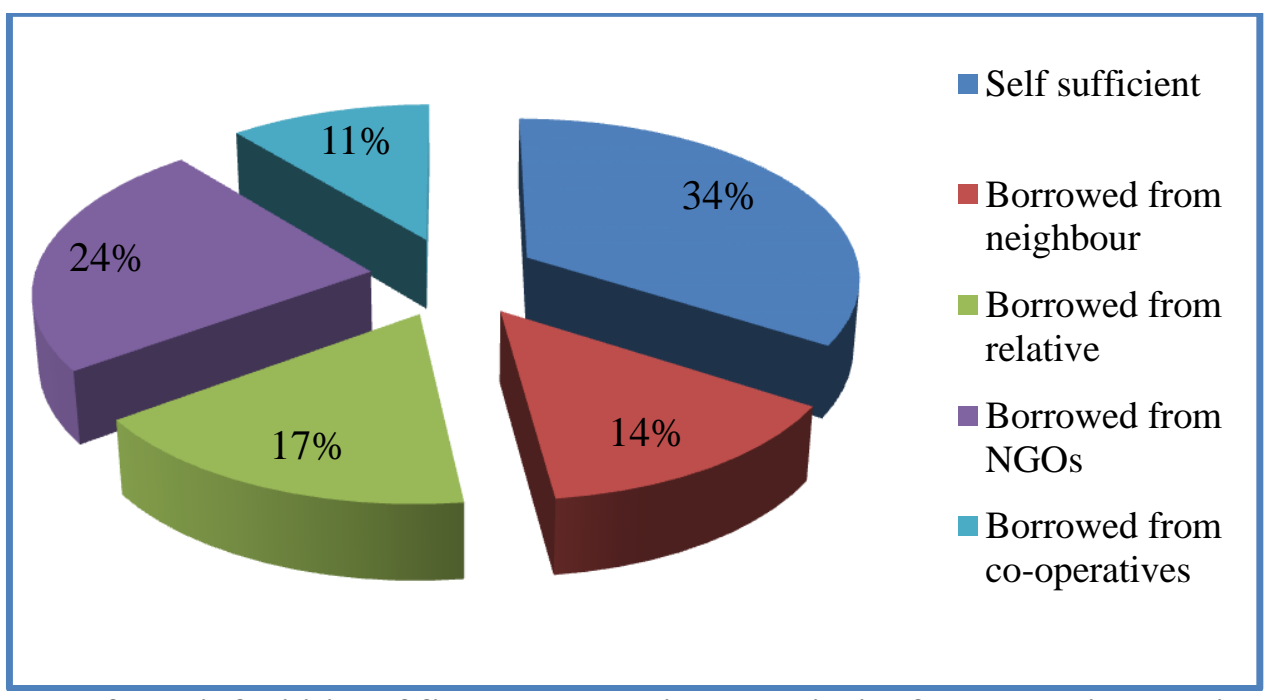

Figure 5. Sources of credit facilities of fishermen and intermediaries for marketing marine fishes in the study area.

\subsection{Housing pattern}

Housing pattern is the indicator of one's economic capacity. The study revealed that $26 \%$ fishermen and intermediaries lived in houses made of bamboo with tin shed, 55\% lived in tin shed house with tin wall. 14\% households were contained straw components and 5\% households contained building (Figure 6). 


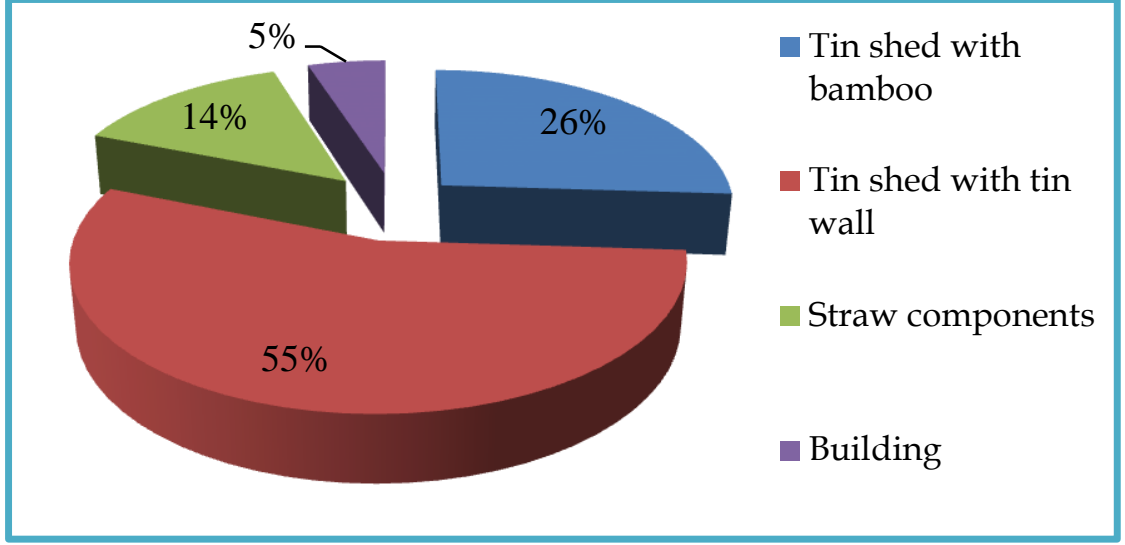

Figure 6. Housing pattern of fishermen and intermediaries in the study area.

\subsection{Use of electricity, television/radio and mobile phone}

Electricity, television/radio and mobile phone facilities are also the determinants of family status. From the study it was observed that, $70 \%$ fishermen and intermediaries enjoyed the facilities of electricity. For recreation and news updates 55\% fishermen and intermediaries used radio/ television. Although most of the fishermen and intermediaries were not so rich and poorly educated but about $95 \%$ had mobile phones to communicate with each other. Only 5\% fishermen and intermediaries did not use mobile phones (Figure 7).

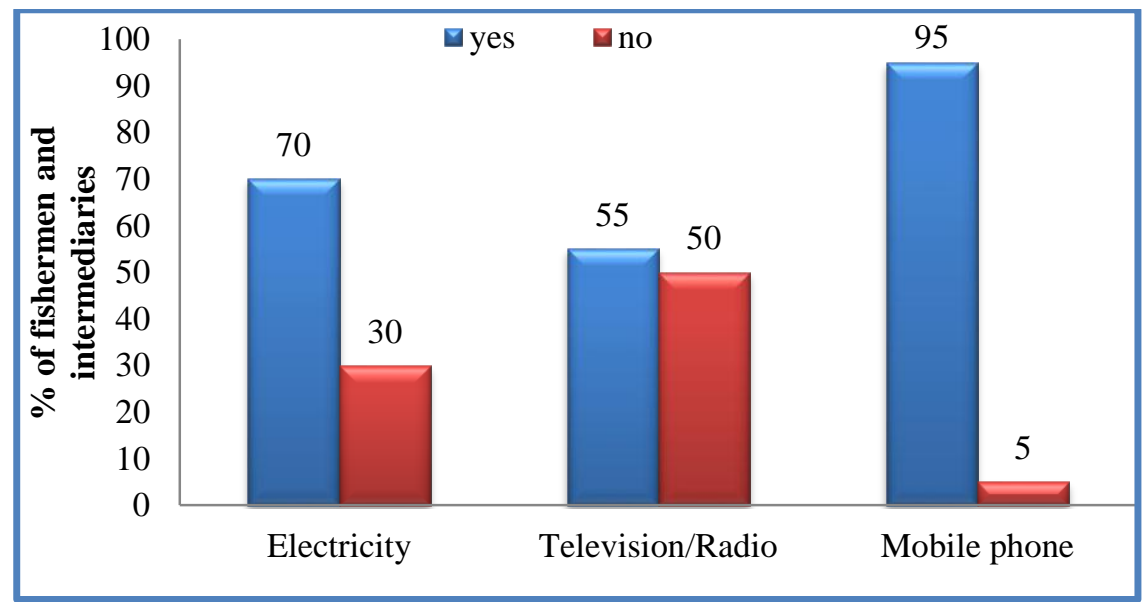

Figure 7. Use of electricity, television/radio and mobile phone of the fishermen and intermediaries in the study area.

\subsection{Sanitary facilities}

It was observed that sanitary conditions of the fishermen and intermediaries were very poor. $20 \%$ fishermen and intermediaries had sanitation built in sand, 59\% had sanitation built in half bricks and $16 \%$ had sanitation built in bricks and 5\% had no sanitary facilities (Figure 8).

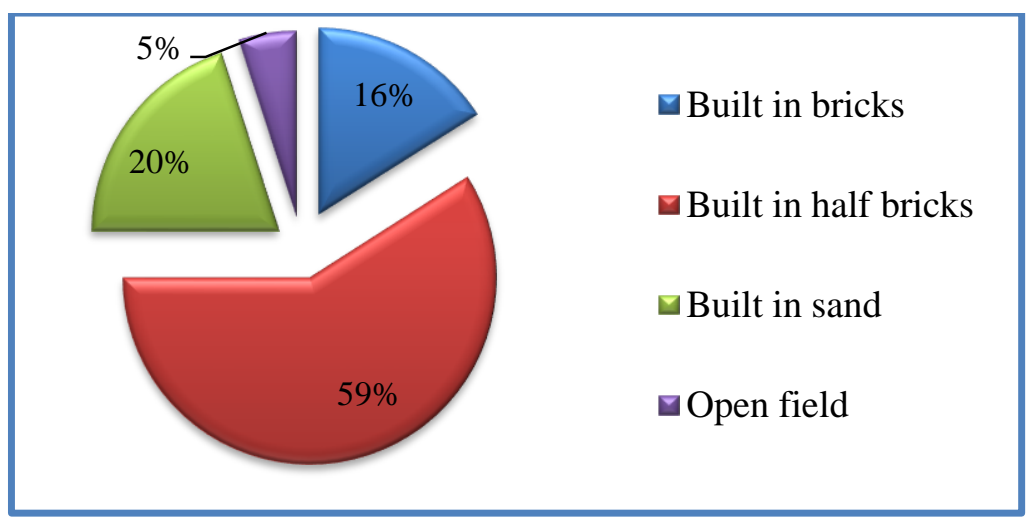

Figure 8. Sanitary facilities of the fishermen and intermediaries in the study area. 
3.9. Constraints in the fishing community

Socio economic constraints such as low income, illiteracy, child education, nutrition, fuel for cooking, house building materials, lack of capital and the increasing fishing pressure etc. were mentioned by fishermen and intermediaries.

\section{Discussion}

From the study found that, the highest $40 \%$ of total respondents were age group of 31 to 40 years and lowest 9 $\%$ were at below age 20 years. The highest $45 \%$ was prevailing in 5-6 members group. Study is more or less similar with (Mursheduzzaman, 2007), who reported that, age group of 31-40 years was the highest 50.00\% of fishermen. Highest 35\% fishermen and intermediaries were illiterate and only 3\% went beyond higher secondary level. Due to illiteracy they are not aware of the socio-economic condition of them and they are unable to change their condition. Similarities found with the previous findings of (Hossain, 2001) who reported that, $65 \%$ riverine fishermen were illiterate, and $5 \%$ had only secondary level.

During the full harvesting time the highest 35\% fishermen and intermediaries earned BDT 400-500 per day and only 7\% earned BDT 700-800 per day. Fishermen whose have own boat, net had the high income and intermediaries whose had own credit facilities get high amount of money. Intermediaries earned more BDT in the marketing chain of the marine fishes because they increased the price of fishes in different ways. Daily income differs from the (Rahman et al.,2012) who reported that the highest number (46\%) of the fishers' daily income ranged between BDT 200 to 300 in the Nijhum Island under Hatiya upazilla of Noakhali district in Bangladesh. Present studies were done for fishermen and intermediaries interview and Rahman et al., 2012 only interviewed the fishermen. The incomes of intermediaries were more than the income of the Fishermen. Besides (Rahman et al., 2012) conducted the study about 3 years ago from the present study and the price of fishes were increased by 3 years and the income of fishermen and intermediaries were also increased.

At the present study found that, $34 \%$ fishermen and intermediaries were self-sufficient and rest were borrowed money from different sources. Similar data found from CPP (Compartmentalization Pilot Project), 1996; reported 70\% of the fishermen borrowed money from moneylenders in Tangail District. Highest 55\% fishermen and intermediaries lived in houses made of tin shed with tin wall and only 5\% lived in building. Fishermen and intermediaries with low income cannot build the building house thus the housing conditions were moderate. Hossain et al. (2002) also reported that 55\% households were tin shed with tin wall and $2 \%$ household were containing building in Teknaf area 70\% fishermen and intermediaries had electricity facility, 50\% had radio/ television. Although most of the fishermen and intermediaries are not so rich and educated but about $95 \%$ have the mobile phone to communicate each other. It was a great improvement for the fishermen and intermediaries that they were introduced with radio, television and mobile phone that helped them in improving their livelihood status.

\section{Conclusions}

Socio-economic condition of the fishermen and intermediaries are not satisfactory and not improved with the time due to loan of high interest, illiteracy, worse weather condition, more intermediaries in the marketing chain etc. If fishermen and intermediaries cannot get education, loan of low interest, proper health and sanitation facilities, their socio-economic condition never be improved. Government and non-government organizations have to take proper steps to improve their socio economic condition by effective planning.

\section{Acknowledgements}

The authors gratefully acknowledge Upazilla Fisheries Officer, Cox's Bazar; Manager of BFDC, Cox's Bazar; fishermen and intermediaries in the study area, for providing valuable information.

\section{Conflict of interest}

None to declare.

\section{References}

Bangladesh Bureau of Statistics (BBS), 2011. Statistical year book of Bangladesh, Ministry of Planning, Government of the People's Republic of Bangladesh.

Chambers R, 1992. Rural Appraisal: Rapid, Relaxed and Participatory. IDS Discussion Paper No. 311, Institute of Development Studies (IDS), Brighton, UK.

CPP, 1996. Socio-economic profile of the professional fishermen and institutional organization.Final report, Bangladesh Water Development Board.Tangail. 
Hossain MS, 2001. Biological aspects of the coastal and marine environment of Bangladesh. Journal of Ocean and Coastal Management, 44:261-282.

Hossain MS, MSN Chowdhury and P Barua, 2002. Artisanal Fisheries Status and Sustainable Management Options in Teknaf. pp. 8-18.

Mursheduzzaman M, 2007. Socio-economic study of the fishermen community of Ichamati river in Santhia upazilla under Pabna district, MS Thesis, Department of Aquaculture, BAU, Mymensingh. pp. 76.

Nabasa J, G Rutwara, F Walker and C Were, 1995. Participatory Rural Appraisal: Practical Experience. Natural Resources Institute (NRI), Greenwich University, London

Rahman M, MM Rahman, MM Hasan and MR Islam, 2012. Livelihood status and the potential of alternating income generating activities of fisher community of nijhum dwip under hatiya upazila of Noakhali district in Bangladesh. Bangladesh Research Publication Journal, 6: 370-379. 